\title{
Phosphorylated cAMP Response Element-Binding Protein as a Molecular Marker of Memory Processing in Rat Hippocampus: Effect of Novelty
}

\author{
Haydée Viola, ${ }^{1}$ Melina Furman, ${ }^{1}$ Luciana A. I. Izquierdo, ${ }^{2}$ Mariana Alonso, ${ }^{1}$ Daniela M. Barros, ${ }^{2}$ \\ Marcia M. de Souza, ${ }^{2}$ Iván Izquierdo, ${ }^{2}$ and Jorge H. Medina ${ }^{1}$ \\ 1/nstituto de Biologia Celular y Neurociencias, Facultad de Medicina, Universidad de Buenos Aires, Paraguay 2155, piso \\ 3, 1121 Buenos Aires, Argentina, and ²Centro de Memoria, Departamento de Bioquimica, Instituto de Biociencias, \\ Universidade Federal do Rio Grande do Sul, Porto Alegre, Brazil
}

From mollusks to mammals the activation of cAMP response element-binding protein (CREB) appears to be an important step in the formation of long-term memory (LTM). Here we show that a 5 min exposure to a novel environment (open field) $1 \mathrm{hr}$ after acquisition of a one-trial inhibitory avoidance training hinders both the formation of LTM for the avoidance task and the increase in the phosphorylation state of hippocampal Ser 133 CREB [phosphorylated CREB (pCREB)] associated with the avoidance training. To determine whether this LTM deficit is attributable to the reduced pCREB level, rats were bilaterally cannulated to deliver Sp-adenosine $3^{\prime}, 5^{\prime}$-cyclic monophosphothioate (Sp-cAMPS), an activator of PKA. Infusion of SpAdenosine $3^{\prime}, 5^{\prime}$-cyclic monophosphothioate Sp-cAMPS to CA1 region increased hippocampal $p C R E B$ levels and restored normal LTM of avoidance learning in rats exposed to novelty. Moreover, a $5 \mathrm{~min}$ exposure to the open field $10 \mathrm{~min}$ before the avoidance training interferes with the amnesic effect of a second $5 \mathrm{~min}$ exposure to the open field $1 \mathrm{hr}$ after avoidance training and restores the hippocampal levels of pCREB. In contrast, the avoidance training-associated activation of extracellular signal-regulated kinases (p42 and p44 mitogenactivated protein kinases) in the hippocampus is not altered by novelty. Together, these findings suggest that novelty regulates LTM formation by modulating the phosphorylation state of CREB in the hippocampus.

Key words: phosphorylated CREB; hippocampus; avoidance training; memory processing; novelty; amnesia
It is widely accepted that long-term memory (LTM) formation requires the onset of the transcriptional and translational machinery in distributed, but selected, neuronal systems (Davis and Squire, 1984; Yin and Tully, 1996; Izquierdo and Medina, 1997; Impey et al., 1998; Silva et al., 1998). Evidence suggests that cAMP-responsive transcription, mediated by the cAMP response element-binding protein (CREB) family of proteins, is a crucial step for the establishment of LTM. Nonassociative learning in Aplysia, avoidance learning in Drosophila and rats, and Pavlovian conditioning and spatial learning in rodents have provided strong evidence that the activation of CREB plays a pivotal role in LTM formation (Bourtchuladze et al., 1994; Bernabeu et al., 1997; Guzowski and McGaugh, 1997; Lamprecht et al., 1997; Impey et al., 1998; Silva et al., 1998). In this context, we and others have shown that memory processing of a one-trial inhibitory avoidance training in rats, a hippocampal-dependent associative learning (Izquierdo and Medina, 1997; Taubenfeld et al., 1999), is associated with an increase in the phosphorylation state of CREB (pCREB) and CRE-mediated gene expression in the hippocam-

\footnotetext{
Received July 17, 2000; revised Sept. 11, 2000; accepted Sept. 11, 2000.

This work was supported by grants from Consejo Nacional de Investigaciones Científicas y Técnicas, Universidad de Buenos Aires (Argentina), Fondo Nacional para las Ciencias y la Tecnología (Argentina), and Programa de Apoio a Núcleos de Excelência (Brazil).

Correspondence should be addressed to Jorge H. Medina, Instituto de Biología Celular y Neurociencias, Facultad de Medicina, Universidad de Buenos Aires, Paraguay 2155 3er piso, Capital Federal (1121), Argentina. E-mail: jmedina@ fmed.uba.ar.

Copyright (C) 2000 Society for Neuroscience $\quad 0270-6474 / 00 / 200001-05 \$ 15.00 / 0$
}

pus (Bernabeu et al., 1997; Impey et al., 1998; Taubenfeld et al., 1999; Cammarota et al., 2000).

Memory is not acquired in its definitive form. It is a temporally graded process during which new information becomes consolidated and stored (McGaugh, 1966, 2000; Izquierdo and Medina, 1997; Izquierdo et al., 1998; Milner et al., 1998). We found recently that an exposure to a novel environment (open field) for $2 \mathrm{~min}, 1 \mathrm{hr}$ after submitting rats to a one-trial inhibitory avoidance training, caused amnesia for the avoidance task measured 1 or several days later (Izquierdo et al., 1999). This finding is in line with the first description of retrograde interference of memory by other experiences performed a century ago (Muller and Pilzecker, 1900).

Therefore, to test whether pCREB is a molecular marker of memory processing in the rat hippocampus, we determined the phosphorylation state of Ser 133 CREB in animals trained in the

This article is published in The Journal of Neuroscience, Rapid Communications Section, which publishes brief, peerreviewed papers online, not in print. Rapid Communications are posted online approximately one month earlier than they would appear if printed. They are listed in the Table of Contents of the next open issue of JNeurosci. Cite this article as: JNeurosci, 2000, 20:RC112 (1-5). The publication date is the date of posting online at www.jneurosci.org.

http://www.jneurosci.org/cgi/content/full/4744 
inhibitory avoidance with or without retrograde interference induced by novelty and in rats that do not perceive the exposure to an open field as new. Here we show that the exposure to a novel environment for $5 \mathrm{~min}, 1 \mathrm{hr}$ after the acquisition of a one-trial inhibitory avoidance, hinders both the formation of inhibitory avoidance memory and the associated increase in CREB phosphorylation in the hippocampus. This amnesic effect is prevented by the infusion of a PKA activator delivered into the CA1 region that increased the hippocampal pCREB levels. Furthermore, a 5 min exposure to the open field 10 min before avoidance training interferes with the amnesic effect of a second 5 min exposure to the open field $1 \mathrm{hr}$ after avoidance training and restores the levels of pCREB. Therefore, we suggest that the level of pCREB in the hippocampus is a molecular marker of memory processing and that novelty modulates memory formation of avoidance training by regulating the phosphorylation state of hippocampal CREB.

\section{MATERIALS AND METHODS}

Subjects. One hundred seventy male Wistar rats (age, 2-3 months; weight, $180-250 \mathrm{gm}$ ) from our own breeding colony were used. The animals were housed in plastic cages, five to a cage, with water and food available ad libitum, under a $12 \mathrm{hr}$ light/dark cycle (lights on at 7:00 A.M.) at a constant temperature of $23^{\circ} \mathrm{C}$.

Behavioral procedures. Inhibitory avoidance was as follows (Bernabeu et al., 1997; Izquierdo et al., 1998). Rats were placed on a $2.5 \mathrm{~cm}$ high, 8.0 $\mathrm{cm}$ wide platform at the left of a $50.0 \times 25.0 \times 25.0 \mathrm{~cm}$ yellow acrylic training apparatus, which floor was a series of parallel $0.2 \mathrm{~cm}$ caliber bronze bars spaced $1.0 \mathrm{~cm}$ apart. Latency to step down onto the grid with all four paws was measured. In the training trial, immediately after this, the animals received a $0.4 \mathrm{~mA}, 4.0 \mathrm{sec}$ scrambled foot shock. In the test session performed $24 \mathrm{hr}$ after training, the procedures were similar except that the foot shock was omitted.

The novel environment was a $50 \mathrm{~cm}$ high, $50 \mathrm{~cm}$ wide, and $39 \mathrm{~cm}$ deep open field with black plywood walls and a brown floor divided into 12 equal squares by black lines. Number of line crossings and rearings (Izquierdo et al., 1999) were measured for a 5 min period.

Three groups of 15 animals were trained in the avoidance task using a $0.4 \mathrm{~mA}$ shock (see Fig. 1A). The first one (trained group, T) was just submitted to this task. The second group (trained plus exposed group, $\mathrm{T}+\mathrm{E}$ ) was exposed for $5 \mathrm{~min}$ to the novel environment $1 \mathrm{hr}$ after the avoidance training. The same was performed to the third group but, in addition, this group was exposed for $5 \mathrm{~min}$ to the open field $10 \mathrm{~min}$ before the avoidance training (exposed plus trained plus exposed group, $\mathrm{E}+\mathrm{T}+\mathrm{E}$ ). All groups were tested at $24 \mathrm{hr}$ after the avoidance training.

Surgery and infusion procedures. Seventy rats were implanted under deep thionembutal anesthesia with 30 ga guide cannulas in the dorsal CA1 region of the hippocampus at the coordinates of the atlas by Paxinos and Watson (1986): anterior, -4.3 ; lateral, \pm 4.0 ; ventral, 3.4. The cannulas were fixed to the skull with dental acrylic (Bernabeu et al., 1997; Izquierdo et al., 1998). After recovery from surgery, these animals were trained in inhibitory avoidance and tested $24 \mathrm{hr}$ later. Three groups of cannulated rats received, 110 min after training, a bilateral infusion of either saline or the PKA activator Sp-adenosine $3^{\prime}, 5^{\prime}$-cyclic monophosphothioate (Sp-cAMPS) dissolved in saline $(0.1$ or $0.5 \mu \mathrm{g} / \mathrm{side})$. Infusions were in all cases bilateral and had a volume of $0.5 \mu$ l. Three other groups of rats were treated as above but, in addition, were exposed to a novel environment $1 \mathrm{hr}$ after training.

Histological examination of cannula placements was performed as described previously (Izquierdo et al., 1997, 1998). Only the behavioral data from animals with the cannula located in the intended site were used.

Biochemical procedures. The rest of the animals were used for biochemical measurements and divided in five experimental groups as shown in Figure 1B: (1) animals withdrawn from their home cages and killed immediately (naive group, $\mathrm{N}$ ); (2) animals submitted to a 5 min session of open-field test and killed $1 \mathrm{hr}$ later (group E); (3) animals trained in the inhibitory avoidance task and killed $2 \mathrm{hr}$ later (group T); (4) animals trained in the inhibitory avoidance box, returned to home cage for $1 \mathrm{hr}$, subjected to a 5 min session in the open-field test, and killed $1 \mathrm{hr}$ latter (group T+E); and (5) animals that received the same treatment as group 4 but, $10 \mathrm{~min}$ before avoidance training, they were subjected to a $5 \mathrm{~min}$ session in the open field (group $\mathrm{E}+\mathrm{T}+\mathrm{E}$ ).
A

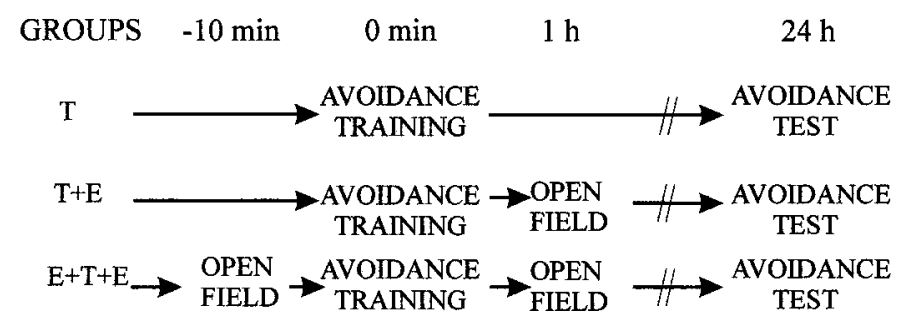

B

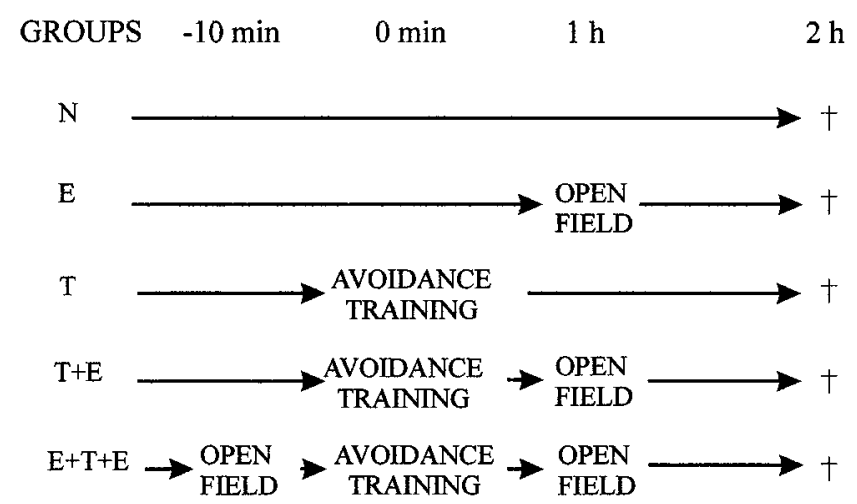

Figure 1. $A$, Scheme showing groups used for the behavioral experiments. $B$, Scheme showing groups used for the biochemical measurements. $\dagger$, Killed.

The entire procedure was performed at $4^{\circ} \mathrm{C}$. After the animals were killed, the brains were immediately removed, and the hippocampi were dissected out, pooled, and homogenized in ice-chilled buffer (20 mM Tris$\mathrm{HCl}, \mathrm{pH}$ 7.4, $0.32 \mathrm{~m}$ sucrose, $1 \mathrm{~mm}$ EDTA, 1 mm EGTA, 1 mm PMSF, 10 $\mu \mathrm{g} / \mathrm{ml}$ aprotinin, $15 \mu \mathrm{g} / \mathrm{ml}$ leupeptin, $50 \mathrm{~mm} \mathrm{NaF}$, and $1 \mathrm{~mm}$ sodim orthovanadate). The homogenate was centrifuged for $10 \mathrm{~min}$ at $900 \times \mathrm{g}$, and the obtained nuclear pellet was resuspended in buffer $(20 \mathrm{~mm}$ Tris-HCl, pH 7.4, 1 mM PMSF, $50 \mathrm{~mm} \mathrm{NaF}$, and 1 mM sodium orthovanadate.) The samples were stored at $-70^{\circ} \mathrm{C}$ until used.

SDS-PAGE and immunoblotting. Samples of nuclear extracts $(12-25 \mu \mathrm{g}$ of protein) were subjected to SDS-PAGE (10\% gels), and immunoblots was performed as described previously (Cammarota et al., 2000). Membranes were incubated with the following antibodies: anti-CREB (1:1000; New England Biolabs, Beverly, MA), anti-pCREB (1:1000; New England Biolabs), anti-p42 and -p44 mitogen-activated protein kinases (MAPKs) (1:2000; New England Biolabs), and anti-activated p42 and p44 MAPKs (1:2000; New England Biolabs). Densitometric analysis of the films was performed by using an MCID Image Analysis System (version 5.02; Imaging Research Inc., St. Catharines, Ontario, Canada). Western blots were developed to be linear in the range used for densitometry.

$P K A$ activity. To investigate whether intrahippocampal infusion of Sp-cAMPS affects PKA activity, the phosphorylation of kemptide was determined as described previously (Bernabeu et al., 1997) using a 2-mm-thick slice taken 10 min after the inf usions from the area in which the infusion cannula was placed.

Data analysis. Statistical analysis was performed by one-way ANOVA using the Duncan's test or Student's $t$ test. Mann-Whitney $U$ test was used for the nonparametric analysis.

\section{RESULTS}

\section{Effect of novelty on the retention of a one-trial avoidance training}

Figure $1 A$ depicts the experimental protocol and the groups of rats used for the behavioral experiments. Confirming and extending recent findings from our laboratories, a 5 min exposure to an 


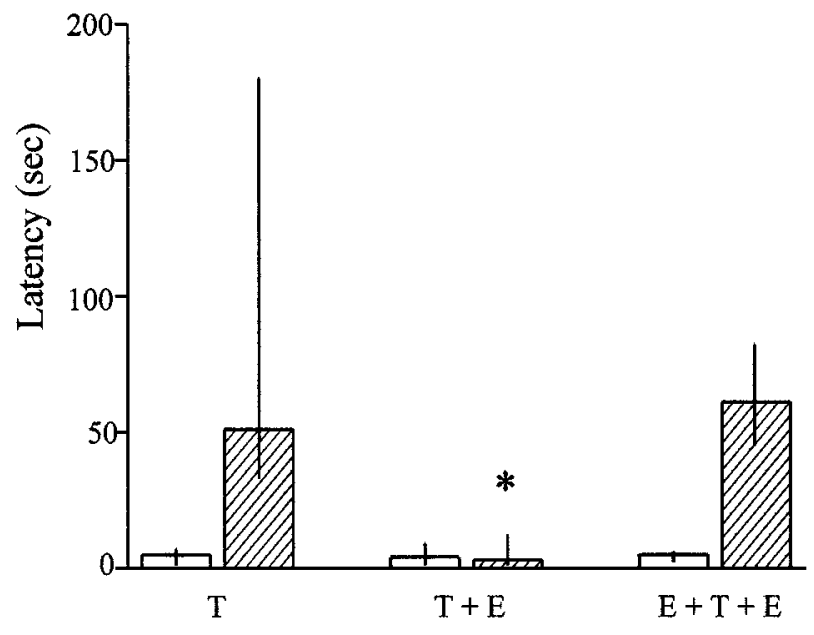

Figure 2. Novelty caused retrograde amnesia for the avoidance learning. Medians (interquartile range) of latencies to step down from the platform of the inhibitory avoidance box in the training session (open bars) and in the test session performed $24 \mathrm{hr}$ later (hatched bars) in the groups of rats shown in Figure $1 A$. ${ }^{*} p<0.002$; Mann-Whitney $U$ test; $n=15$ per group.

open field $1 \mathrm{hr}$ after training rats in a one-trial inhibitory avoidance task caused retrograde amnesia for the avoidance learning (Fig. 2). The amnesic effect of the novelty presented $1 \mathrm{hr}$ after avoidance training was totally blocked when rats were exposed to the open field $10 \mathrm{~min}$ before the avoidance training. In other words, pretraining exposure to the open field disrupted the amnesic effect of the post-training exposure to the open field. In this group of animals, the post-training exposure was not recognized as novelty, because the number of crossings and rearings per session were lower in the second open-field trial than in the first one (crossings, $77.3 \pm 3.7$ vs $53.6 \pm 3.4$; rearings, $24.7 \pm 1.5$ vs $15.6 \pm 1.1$, for the first and second open-field exposure, respectively; $p<0.0001$; Student's $t$ test). Therefore, the perception of novelty is associated with its deleterious effect on long-term avoidance memory.

\section{Effect of novelty on the avoidance-induced increase in the phosphorylation state of CREB in the hippocampus}

We and others have found previously that one-trial inhibitory avoidance training in rats is specifically associated with a timedependent and NMDA receptor-dependent increase in Ser 133 pCREB in the hippocampus without changes in total CREB protein (Bernabeu et al., 1997; Impey et al., 1998; Taubenfeld et al., 1999; Cammarota et al., 2000). Given that CREB has an important role in LTM formation (for references, see Silva et al., 1998), that inhibitory avoidance training results in CRE-mediated gene expression in the hippocampus (Impey et al., 1998), and that phosphorylation of CREB at Ser 133 is associated with CREBregulated gene expression (Montminy, 1997), we determined the levels of Ser 133 pCREB in the experimental groups shown in Figure $1 B$.

Representative immunoblots using an antibody that specifically detects Ser 133 pCREB and the densitometric analysis of the data are shown in Figure 3, $A$ and $B$. Confirming previous findings, inhibitory avoidance training results in a large increase in the phosphorylation state of CREB in hippocampal extracts $(+127 \%$; $p<0.05 ; n=9) 2 \mathrm{hr}$ after acquisition of the avoidance training, without altering total CREB protein levels. Rats exposed to the novel environment for 5 min (group E) exhibited a modest and
A
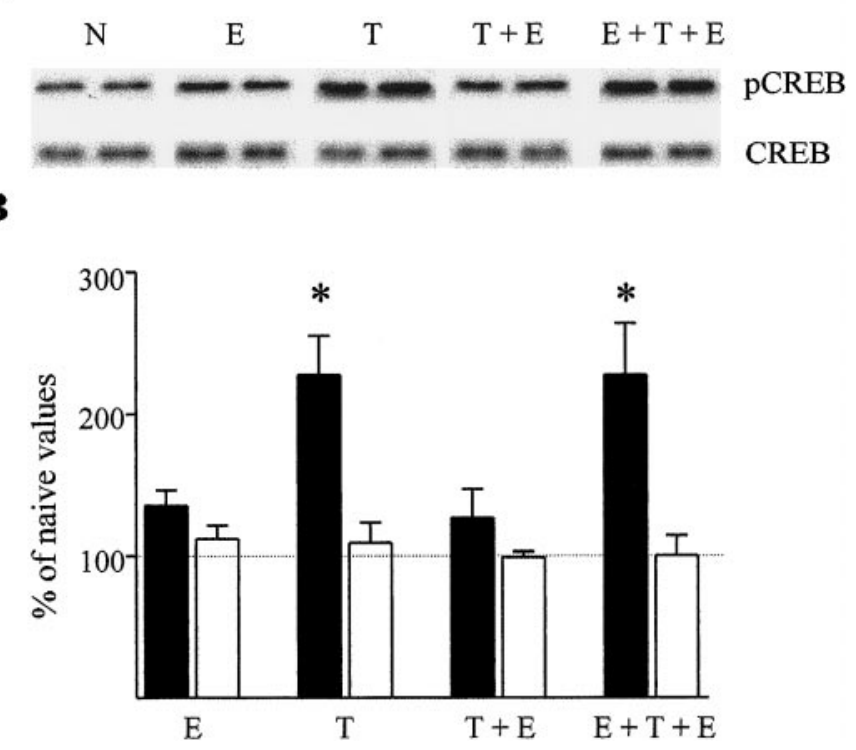

Figure 3. Novelty decreased the hippocampal pCREB levels associated with the inhibitory avoidance training. $A$, Representative Western blots with anti-pCREB and anti-CREB antibodies in hippocampal nuclear samples of rats from experimental groups shown in Figure $1 B$. B, Densitometric analysis of the data. Data are expressed as mean \pm SEM percentage of naive control values for pCREB (filled bars) and CREB (open bars). The number of animals per group ranged between eight and nine. ${ }^{*} p<0.05$ with respect to $\mathrm{E}$ and $\mathrm{T}+\mathrm{E}$ groups; Duncan's test.

nonsignificant increase $(+35 \% ; n=8)$ in pCREB levels. Rats exposed to the open field $1 \mathrm{hr}$ after acquisition of the avoidance training (group $\mathrm{T}+\mathrm{E}$ ) showed a significant decrease in the phosphorylation state of CREB compared with rats subjected only to the avoidance task $(+26$ vs $+127 \%$ of naive control values; $p<$ $0.05 ; n=9)$. Therefore, post-training novelty caused retrograde amnesia of the avoidance training (Fig. 2) and blocked the increase in hippocampal pCREB levels that accompanied this training (Fig. $3 B$ ). More importantly, a 5 min exposure to the open field $10 \mathrm{~min}$ before avoidance training not only abolished the amnesic effect of a second $5 \mathrm{~min}$ exposure to the open field $1 \mathrm{hr}$ after avoidance training (Fig. 2) but also restored the levels of pCREB in the hippocampus (Fig. 3B). As expected, the exploration of the open field in the second session was significantly lower than in the first one (crossings, $43 \pm 6.3$ vs $82.4 \pm 7.2 ; p<0.001$; rearings, $12.5 \pm 2.2$ vs $21.3 \pm 1.6 ; p<0.01$; Student's $t$ test). Moreover, it is important to mention here that the performance of rats in the open field given $1 \mathrm{hr}$ after the avoidance training (group $\mathrm{T}+\mathrm{E}$ ) is similar to that observed in exposed rats (crossings, $73 \pm 3.2$ vs $76.7 \pm 5.5$; rearings, $25 \pm 2.2$ vs $29.7 \pm 1.2 ; p>$ 0.05 ; Student's $t$ test), indicating that the avoidance training did not alter the subsequent performance of rats in the open field.

There is an emerging body of evidence demonstrating that different training procedures result in activation of extracellular signal-regulated kinases (p42 and p44 MAPKs) (Atkins et al., 1998; Crow et al., 1998). Given that p42 and p44 MAPKs couples PKA and PKC to CREB phosphorylation in hippocampus (Roberson et al., 1999) and that we found recently an activation of p42 and p44 MAPKs 2 hr after acquisition of inhibitory avoidance training (Cammarota et al., 2000), we next determined whether the exposure to a novel environment $1 \mathrm{hr}$ after an avoidance training modulates the avoidance-associated activation of MAPKs. For this purpose, we used immunoblot techniques to detect dually phos- 


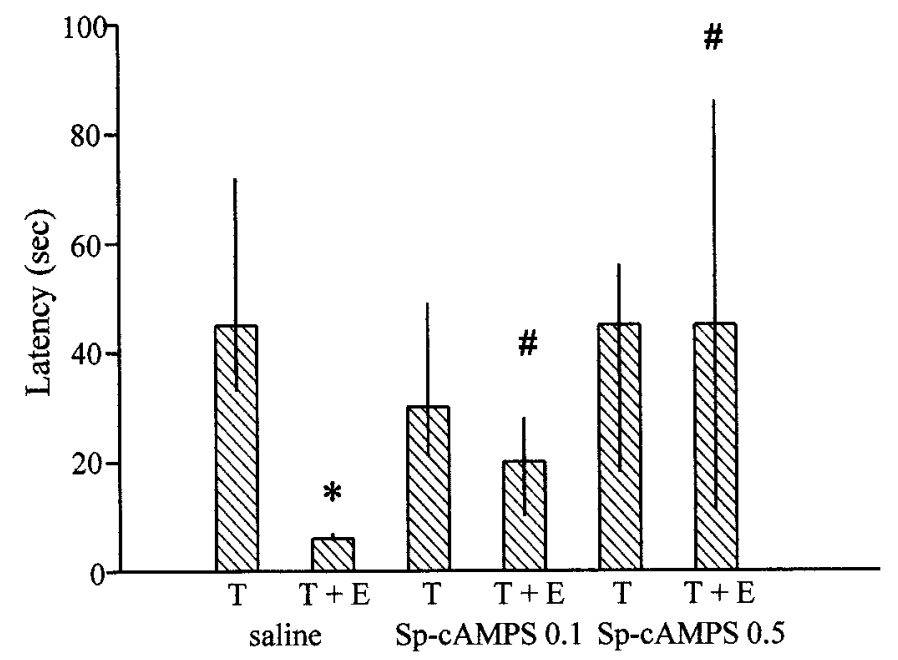

Figure 4. Infusion of Sp-cAMPS into the CA1 region of the dorsal hippocampus overcomes novelty induced-amnesia. Medians (interquartile range) of latencies to step down from the platform of inhibitory avoidance box in the test session performed $24 \mathrm{hr}$ after training. Rats were trained in the avoidance task or received this training plus an exposure to the open field $1 \mathrm{hr}$ later. In all cases, a bilateral CA1 injection of saline or Sp-cAMPS ( 0.1 or $0.5 \mu \mathrm{g} / \mathrm{side}$ ) was administered $110 \mathrm{~min}$ after the avoidance training. ${ }^{*} p<0.002$ versus $\mathrm{T}$ rats injected with saline; $\# p<$ 0.02 versus $\mathrm{T}+\mathrm{E}$ rats injected with saline; Mann-Whitney $U$ test; $n=$ $10-11$ per group.

phorylated, activated p42 and p44 MAPKs. In contrast to what happened with hippocampal Ser 133 CREB, post-training novelty did not alter the increased levels of phospho-p42 and -p44 MAPKs associated with the avoidance training (phospho-p42 MAPK: trained, $130.7 \pm 11 \%$ vs trained plus exposed, $128.1 \pm$ 9.2\% with respect to naive values, $n=8$; phospho-p44 MAPK: trained, $209 \pm 39 \%$ vs trained plus exposed, $195 \pm 34 \%$ with respect to naive values, $n=8$ ).

\section{Infusion of Sp-cAMPS into the CA1 region of the hippocampus blocked novelty-induced amnesia}

Given that memory formation of avoidance training requires PKA activation and is associated with an increased phosphorylation of CREB and CRE-mediated gene expression (Bernabeu et al., 1997; Impey et al., 1998; Taubenfeld et al., 1999; Cammarota et al., 2000), we next determined whether in vivo activation of PKA and the subsequent increment of pCREB levels in the hippocampus is able to overcome the amnesic effect of novelty on avoidance training. Bilateral microinjection of the PKA activator Sp-cAMPS $(0.1$ and $0.5 \mu \mathrm{g} / 0.5 \mu \mathrm{l})$ in the CA1 region of the dorsal hippocampus of $\mathrm{T}+\mathrm{E}$ rats, $110 \mathrm{~min}$ after avoidance training (i.e., $10 \mathrm{~min}$ before the increase in pCREB levels associated with the avoidance task; see Fig. $1 A$ ), reverted the amnesic effect of novelty on avoidance training (Fig. 4). Sp-cAMPS $(0.5 \mu \mathrm{g})$ given into CA1 region $110 \mathrm{~min}$ after avoidance training increased by $40 \%$ hippocampal pCREB levels in $\mathrm{T}+\mathrm{E}$ rats (saline, $336 \pm 35.5$ vs Sp-cAMPS, $471 \pm 40.8$ in relative units; $p<0.03$; Student's $t$ test; $n=7)$. As expected, Sp-cAMPS $(0.1 \mu \mathrm{g})$ increased PKA activity by $30 \%$ (saline, $301.8 \pm 22.3$ vs Sp-cAMPS, $399 \pm 35.3$ pmol of ${ }^{32} \mathrm{P}$-kemptide per minute per milligram of protein; $n=5$; $p<0.05) 10 \mathrm{~min}$ after injection. Therefore, activation of hippocampal PKA blocked novelty-induced amnesia and restored normal LTM.

\section{DISCUSSION}

The main finding of the present study is that the levels of pCREB in the hippocampus parallels the behavioral index of a memory trace of a hippocampal-dependent learning task. This is based on three series of data. First, learning of the avoidance task is associated with an increase in hippocampal pCREB levels. Second, this increase was abolished by the exposure to a novel environment $1 \mathrm{hr}$ after avoidance training (Fig. 3), a behavioral procedure that induces retrograde amnesia for the avoidance task (Fig. 2). Moreover, this novelty-induced amnesia of the avoidance training was overcome by the bilateral infusion of Sp-cAMPS into the CA1 region of the hippocampus (Fig. 4). As expected, Sp-cAMPS produced a 30\% increase in PKA activity and was able to increase the hippocampal pCREB levels in the $\mathrm{T}+\mathrm{E}$ rats. Third, a pretraining exposure to a novel environment that blocks the amnesic effect of a post-training exposure to an open field on avoidance training restored hippocampal pCREB levels. Therefore, LTM formation of an avoidance training is associated with some optimal level of pCREB in the hippocampus $2 \mathrm{hr}$ after training.

What is the mechanism for the novelty-induced disruption of both pCREB increase and memory formation of the avoidance training? The molecular mechanisms of one-trial inhibitory avoidance are now known to involve a sequence of molecular events in the hippocampus, including an early NMDA- and calcium/calmodulin-dependent protein kinase II-dependent phase and a crucial late PKA- and protein synthesis-dependent phase (Bernabeu et al., 1997; Izquierdo and Medina, 1997). This late phase, which occurs 2-6 hr after acquisition, is necessary for the persistence of memory of this and other hippocampaldependent tasks (Carew, 1996; Bernabeu et al., 1997; Bourtchuladze et al., 1998) (see also McGaugh, 2000).

This late phase is also associated with an increased phosphorylation of CREB (Bernabeu et al., 1997; Taubenfeld et al., 1999; Cammarota et al., 2000) and CRE-mediated gene expression (Impey et al., 1998; Cammarota et al., 2000). In addition, the intrahippocampal infusion of CREB antisense oligonucleotides blocks consolidation, but not acquisition, of a water-maze learning (Guzowski and McGaugh, 1997; McGaugh, 2000). Together, these findings support the hypothesis that the late phase of memory consolidation involves PKA-mediated activation of CREB (Izquierdo and Medina, 1997; Silva et al., 1998; McGaugh, 2000). Post-training novelty may affect memory consolidation of the avoidance learning because of a resetting of its underlying molecular mechanisms (Morris, 1998; Izquierdo et al., 1999). The detection of novelty depends, at least in part, on hippocampal systems (Knight, 1996; Zhu et al., 1997). Interestingly, a 4 min exposure to a novel environment caused, after $60 \mathrm{~min}$, an increase in hippocampal CRE binding (Kinney and Routtenberg, 1993). In our experiments, post-training novelty is presented when the molecular mechanisms of memory formation of the avoidance task are on their way toward the crucial late PKA-dependent phase. In line with this assumption, the exposure to a novel environment before or too late $(6 \mathrm{hr})$ after acquisition did not disrupt memory consolidation of the avoidance training (Izquierdo et al., 1999). Our present findings showing that the exposure to a novel environment $1 \mathrm{hr}$ after acquisition of avoidance training is accompanied by a marked decrease in pCREB levels in the hippocampus (Fig. $3 B$ ) are consistent with this hypothesis. Moreover, when post-training exposure to an open field is not perceived as novelty, by virtue of a pretraining exposure to the novel environment, retention test performance of the avoidance task is normal and pCREB levels are restored.

It is important to stress here that phosphorylation of CREB is just one component of a complex biochemical cascade that leads 
to gene expression, which also involves recruitment of CREB binding proteins and their binding to CRE sequence, in combination with other transcription factors (Montminy, 1997).

Consistent with hebbian models of synaptic plasticity and in remarkable parallel with the present findings, the exposure to a novel environment $1 \mathrm{hr}$ after induction of long-term potentiation in CA1 region of the hippocampus hinders LTP expression (Xu et al., 1998).

In conclusion, our results, together with those reporting that fornix lesions disrupts both inhibitory avoidance memory and the increased pCREB levels associated with this task (Taubenfeld et al., 1999), endorse the hypothesis that pCREB is a molecular marker of memory processing in rat hippocampus. A major question arises from this study. Which of the plethora of CREBregulated genes are specifically involved in memory consolidation? Answer to this question should give us interesting clues on the important role of CREB family of transcription factors in the establishment of long-lasting memories.

\section{REFERENCES}

Atkins CM, Selcher JC, Petraitis JJ, Trzaskos JM, Sweatt JD (1998) The MAPK cascade is required for mammalian associative learning. Nat Neurosci 1:602-609.

Bernabeu R, Bevilaqua L, Ardenghi P, Bromberg E, Schmitz P, Bianchin M, Izquierdo I, Medina JH (1997) Involvement of hippocampal $\mathrm{cAMP} / \mathrm{cAMP}$-dependent protein kinase signaling pathways in a late memory consolidation phase of aversively motivated learning in rats. Proc Natl Acad Sci USA 94:7041-7046.

Bourtchuladze R, Frenguelli B, Blendy J, Schutz G, Silva A (1994) Deficient long-term memory in mice with a targeted mutation of the cAMP-responsive element binding protein. Cell 79:59-68.

Bourtchuladze R, Abel T, Berman N, Gordon R, Lapidus K, Kandel ER (1998) Different training procedures recruit either one or two critical periods for contextual memory consolidation, each of which requires protein synthesis and PKA. Learn Mem 5:365-374.

Cammarota M, Bevilaqua LRM, Ardenghi P, Paratcha G, Levi de Stein M, Izquierdo I, Medina JH (2000) Learning-associated activation of nuclear MAPK, CREB and Elk-1, along with Fos production, in the rat hippocampus after a one-trial avoidance learning: abolition by NMDA receptor blockade. Mol Brain Res 76:36-46.

Carew TJ (1996) Molecular enhancement of memory formation. Neuron 16:5-8.

Crow T, Xue-Bian JJ, Siddiqi V, Kang Y, Neary JT (1998) Phosphorylation of mitogen-activated protein kinase by one-trial and multi-trial classical conditioning. J Neurosci 18:3480-3487.

Davis HP, Squire LR (1984) Protein synthesis and memory: a review. Psychol Bull 96:518-559.
Guzowski JF, McGaugh JL (1997) Antisense oligodeoxynucleotidemediated disruption of hippocampal cAMP response element binding protein levels impairs consolidation of memory for water maze training. Proc Natl Acad Sci USA 94:2693-2698.

Impey S, Smith DM, Obrietan K, Donahue R, Wade C, Storm DR (1998) Stimulation of cAMP response element (CRE)-mediated transcription during contextual learning. Nat Neurosci 1:595-601.

Izquierdo I, Medina JH (1997) Memory formation: the sequence of biochemical events in the hippocampus and its connection to activity in other brain structures. Neurobiol Learn Mem 68:285-316.

Izquierdo I, Barros DM, Izquierdo L, Mello e Souza T, Souza M, Medina JH (1998) Mechanisms for memory types differ. Nature 393:635-636.

Izquierdo I, Schroeder N, Netto CA, Medina JH (1999) Novelty causes time-dependent retrograde amnesia for one-trial avoidance in rats through NMDA receptor- and CAMKII-dependent mechanisms in hippocampus. Eur J Neurosci 11:3323-3328.

Kinney W, Routtenberg A (1993) Brief exposure to a novel environment enhances binding of hippocampal transcription factors to their DNA recognition elements. Mol Brain Res 20:147-152.

Knight RT (1996) Contribution of human hippocampal region to novelty detection. Nature 383:256-259.

Lamprecht R, Hazvi S, Dudai Y (1997) cAMP response element binding protein in the amygdala is required for long- but not short-term conditioned taste aversion memory. J Neurosci 17:8443-8450.

McGaugh JL (1966) Time-dependent processes in memory storage. Science 153:1351-1359.

McGaugh JL (2000) Memory: a century of consolidation. Science $87: 248-251$.

Milner B, Squire LR, Kandel ER (1998) Cognitive neuroscience and the study of memory. Neuron 20:445-468.

Montminy M (1997) Transcriptional regulation by cyclic AMP. Annu Rev Biochem 66:807-822.

Morris RGM (1998) Down with novelty. Nature 394:834-835.

Muller GE, Pilzecker A (1900) Experimentelle Beitrage zur Lehre vom Gedachtniss. Z Psychol 1:1-288.

Paxinos G, Watson C (1986) The rat brain in stereotaxic coordinates. San Diego: Academic.

Roberson ED, English JD, Adams JP, Selcher JC, Kondratick C, Sweatt JD (1999) The mitogen-activated protein kinase cascade couples PKA and $\mathrm{PKC}$ to $\mathrm{CAMP}$ response element binding protein phosphorylation in area CA1 of hippocampus. J Neurosci 19:4337-4348.

Silva AJ, Kogan JH, Frankland PW, Kida S (1998) CREB and memory. Annu Rev Neurosci 21:127-148.

Taubenfeld SM, Wiig KA, Bear MF, Alberini CM (1999) A molecular correlate of memory and amnesia in the hippocampus. Nat Neurosci 2:309-310.

Xu L, Anwyl R, Rowan MJ (1998) Spatial exploration induces a persistent reversal of long-term potentiation in rat hippocampus. Nature 394:891-894.

Yin JCP, Tully T (1996) CREB and the formation of long-term memory. Curr Opin Neurobiol 6:204-208.

Zhu XO, McCabe BJ, Aggleton JP, Brown MW (1997) Differential activation of the rat hippocampus and perirhinal cortex by novel visual stimuli and a novel environment. Neurosci Lett 229:141-143. 